Family Profile No. 10, 2018

\title{
Attitudes on Women's Roles in the Home: 1986-2016
}

\section{Author: Colette A. Allred}

Women's labor force participation rose rapidly throughout the middle of the twentieth century, eventually slowing down in the 1990s before declining gradually since 1999. Today, the majority of working-age women (57\%) are in the labor force (Bureau of Labor Statistics 2017). During the past few decades, attitudes on women's employment have also changed. This profile uses the General Social Survey (GSS) to examine attitudes toward women's roles in the home among adults aged 18 and older in the United States. Views on women's roles in the home and the perceived effect of mothers' employment on their young children are considered over time and for both men and women.

\section{Attitudes on Men and Women's Work and Home Roles, 1986-2016}

Support for the male breadwinner model is declining. Figure 1 shows the percentage of adults who agree with the statement "it is much better for everyone involved if the man is the achiever outside the home and the woman takes care of the home and family."

- In 2016, about one-quarter (27\%) of adults reported they think it is better for men to work and for women to tend to the home. This is a marked decrease since 1986 when nearly half agreed.

- This trend is striking because over time, the percentage of women aged 16 and older who were employed remained fairly stable, with $54 \%$ of women in the labor force in 2016. The gap in men and women's labor force participation has declined largely due to a decline in the share of men in the labor force.
Figure 1. Percentage of Employed Men and of Women 16+ and Percentage Who Report It Is Better for Men to Work, Women to Tend Home

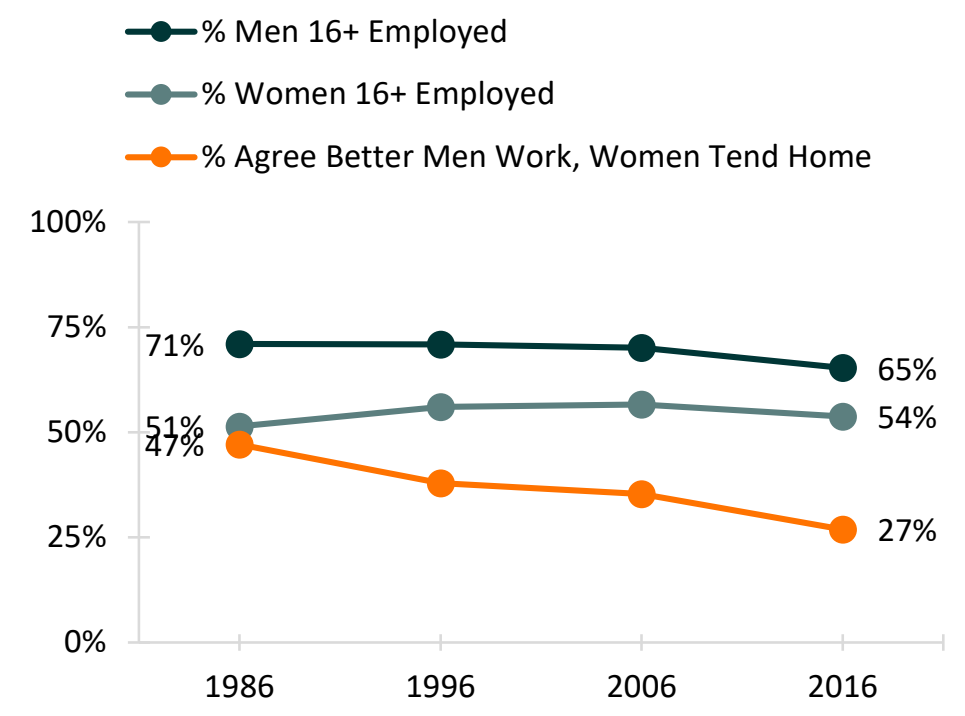

Source: NCFMR analyses of General Social Survey, 1986-2016; Bureau of Labor Statistics, 1986-2016

Attitudes on Men and Women's Work and Home Roles, by Gender

Figure 2. Percentage Who Report It Is Better for Men to Work, Women to Tend Home, by Gender

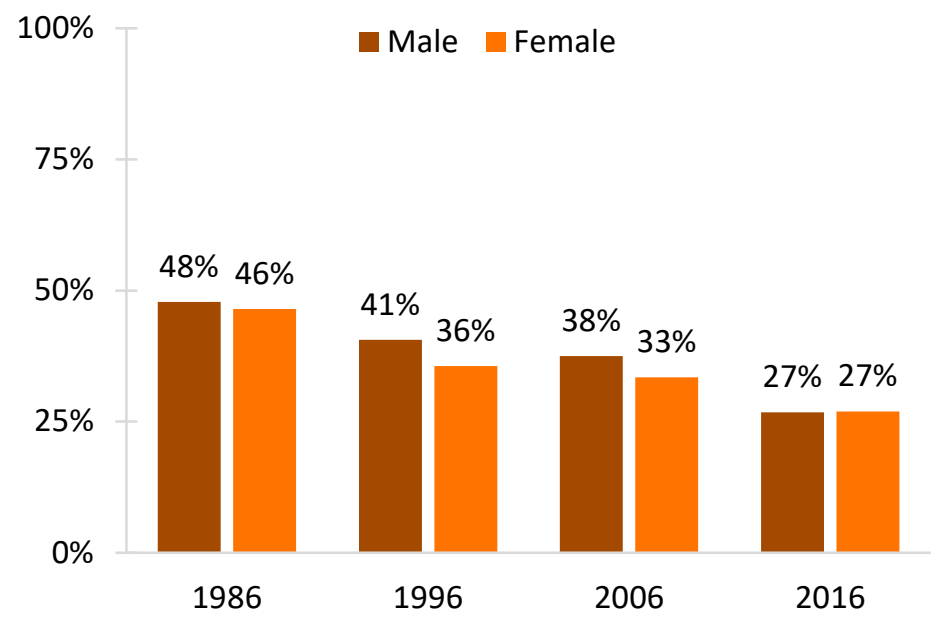

Source: NCFMR analyses of General Social Survey, 1986-2016
Although only a minority of adults express support for a male breadwinner model, there are some gender differences in these trends, as shown in Figure 2.

- In 1986 and 2016, roughly equal shares of men and women agreed that it is better for men to work and women to stay home.

- Declining support for the male breadwinner model occurred earlier for women than for men. The greatest decline for women occurred between 1986 and 1996. In contrast, among men there has been a more gradual decline--half of men's decline occurred within the last decade 
Attitudes about Mothers' Employment and Preschool-Age Children

Over the last 30 years, the share of U.S. adults who agree with the statement "a preschool child is likely to suffer if his or her mother works" has sharply declined (Figure 3).

- Since 1986, the share of U.S. adults who believe that preschool-age children of working mothers suffer has decreased from about half to $28 \%$.

- The decline has been most rapid in the past ten years, falling from $41 \%$ to $28 \%$. This rate of change is larger than that of the previous 20 years combined.

- At the same time, the percentage of mothers with preschool-age children who work has increased. Thirty years ago, slightly more than half of women with young children participated in the labor force, whereas in 2016 the proportion is nearly two-thirds.
Figure 3. Percentage of Mothers with Preschool-Age Children at Home Who Are in the Labor Force and Percentage Who Report Preschool-Age Children Suffer if Mother Works

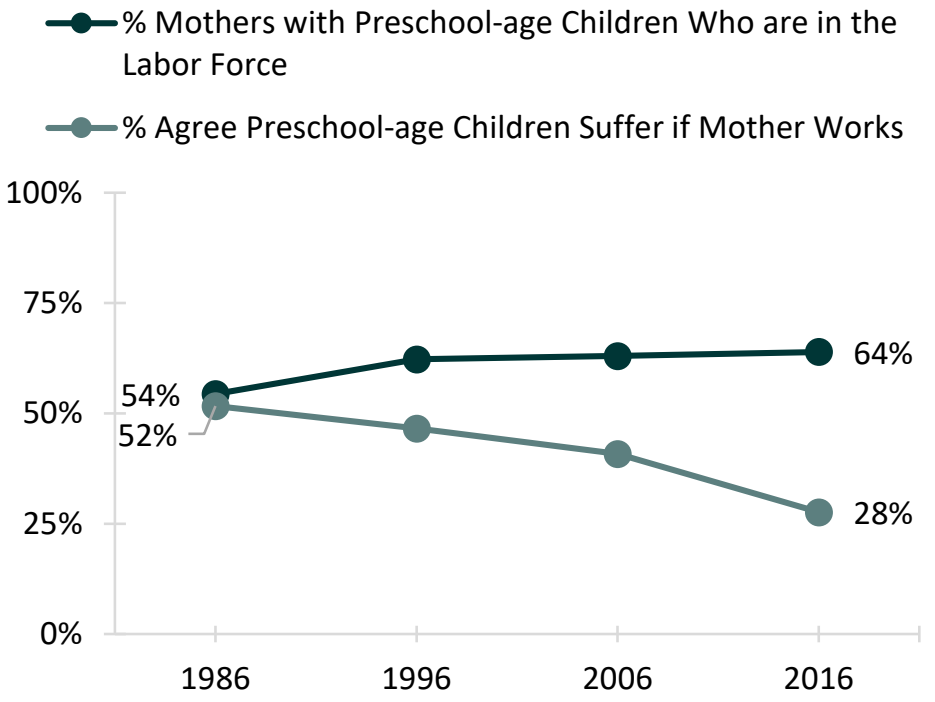

Source: NCFMR analyses of General Social Survey, 1986-2016; Bureau of Labor Statistics, 1986-2016

\section{Attitudes on Mothers' Employment and Their Preschool-Age Children, by Gender}

Figure 4. Percentage Who Report Preschool-Age Children Suffer if Mother Works, by Gender

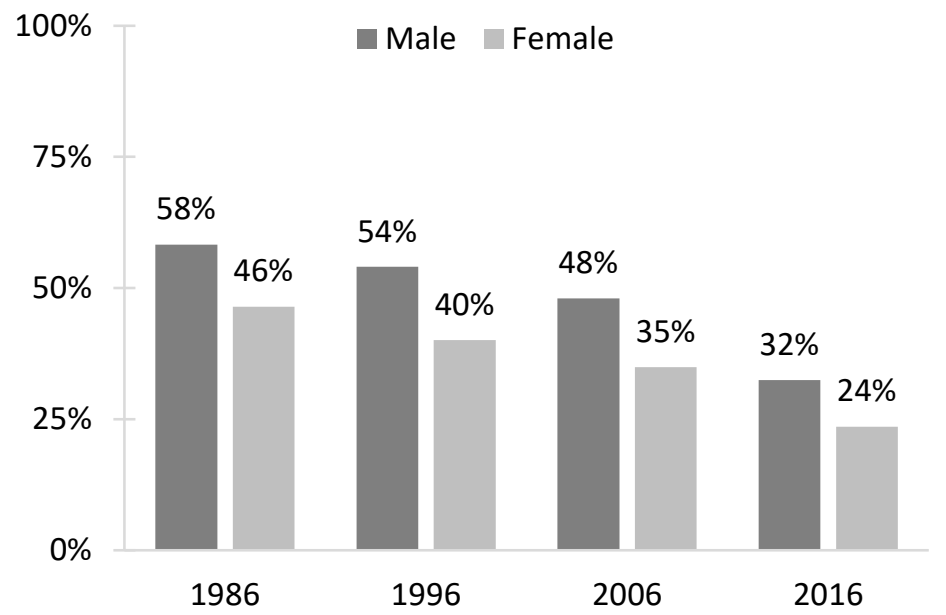

Although both men and women exhibited a downward trend in agreeing that a working mother is harmful for young children, a persistent gender gap exists (Figure 4).

- Over the past 30 years, men agreed more often than women that children are harmed when mothers work. Today, however, only one-third (32\%) of men and onequarter $(24 \%)$ of women believe that women's employment hurts preschool age children.

- The gender gap has narrowed from a 12-point differential in 1986 to an 8-point gap in 2016.

Source: NCFMR analyses of General Social Survey, 1986-2016; Bureau of Labor Statistics, 1986-2016

\section{Data Source:}

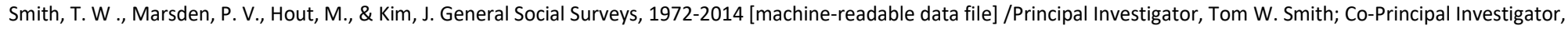

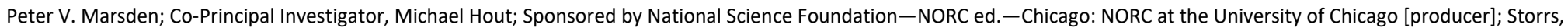
CT: The Roper Center for Public Opinion Research, University of Connecticut [distributor], 2015.

1 data file (57,061 logical records) + 1 codebook (3,567p.). -- (National Data Program for the Social Sciences, No. 22).

References:

Bureau of Labor Statistics (April 2017). Women in the labor force: A databook. Report 1065. United States Department of Labor.

\section{Suggested Citation:}

Allred, C. A. (2018). Attitudes on women's roles in the home: 1886-2016. Family Profiles, FP-18-10. Bowling Green, OH: National Center for Family \& Marriage Research. https://doi.org/10.25035/ncfmr/fp-18-10.

\begin{tabular}{|c|c|c|}
\hline BESU. & $\begin{array}{l}\text { National Center for } \\
\text { Family \& Marriage Research }\end{array}$ & $\begin{array}{l}\text { http://www.bgsu.edu/ncfmr } \\
\text { ncfmr@bgsu.edu }\end{array}$ \\
\hline BOWLING GR & EN STATE UNIVERSITY & (419) 372-3119 \\
\hline
\end{tabular}

